Country Practice

\section{Rural Norfolk: GP as a community property}

I NEIL STEVENSON

A summer Sunday aftemoon, the garden is looking very pleasing,
and the rasss

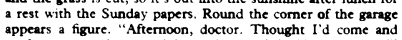

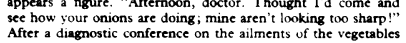

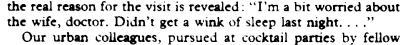

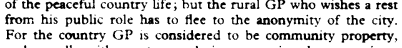

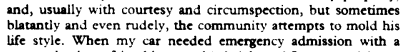

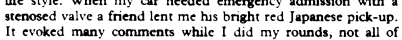

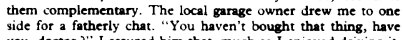

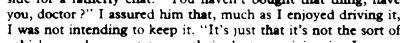

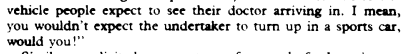

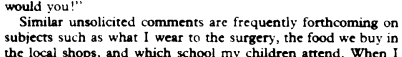

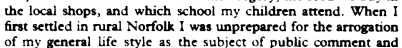

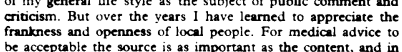

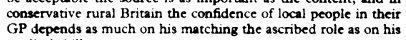

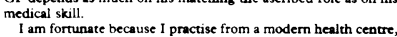

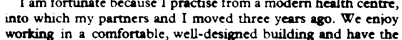

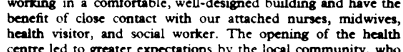

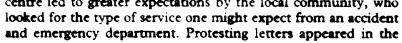

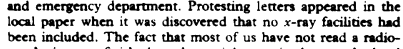

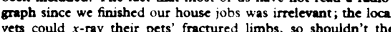

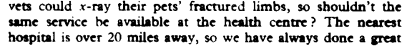

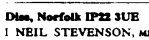

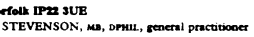

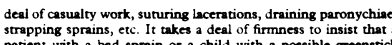

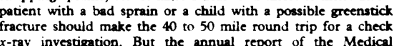

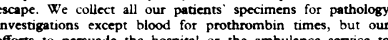

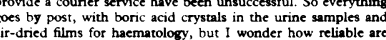

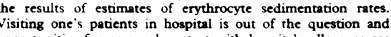

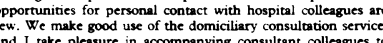

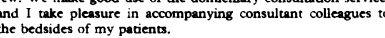

Enthusesedc peadents

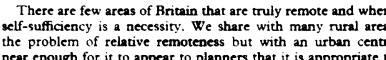

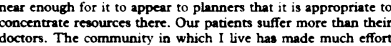

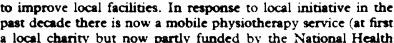

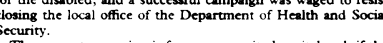

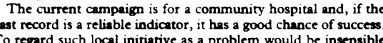

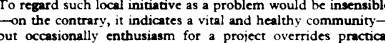

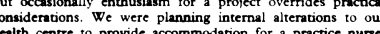

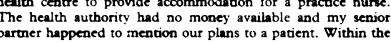

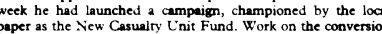

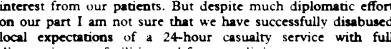

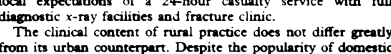

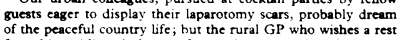

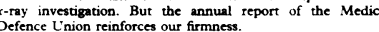

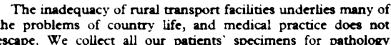

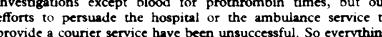

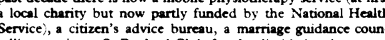

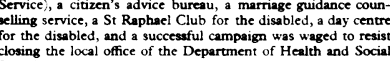

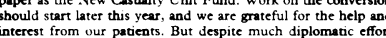
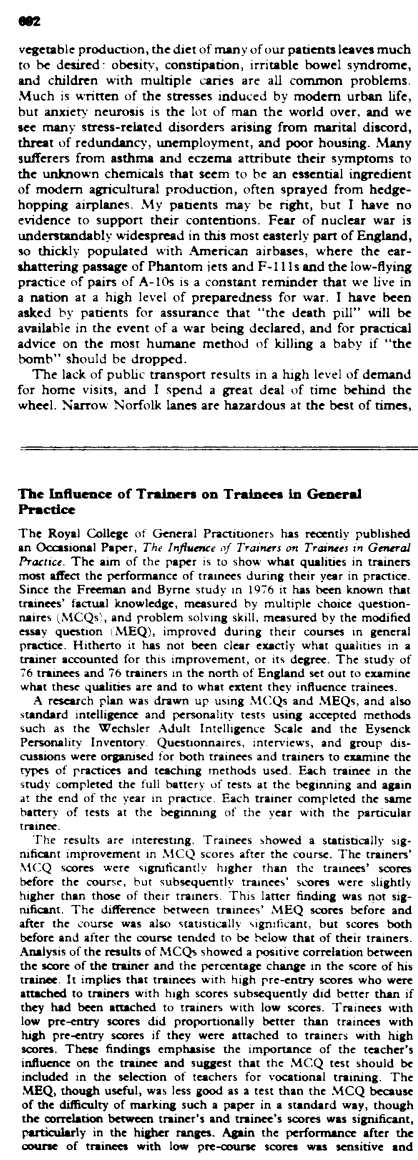

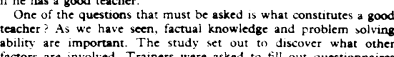

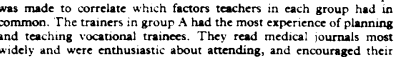

\begin{tabular}{|c|c|}
\hline BRr & 000 \\
\hline
\end{tabular}

\title{
An argument for the MRCGP exam
}

RICHARD HOBBS

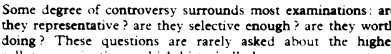

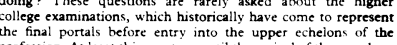

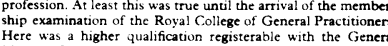

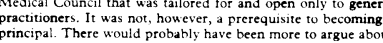

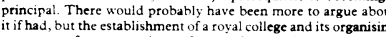

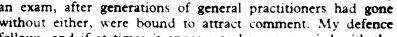

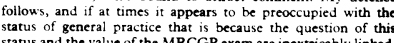

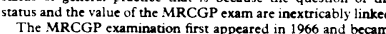

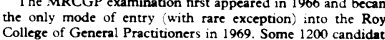

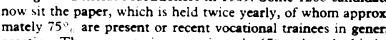

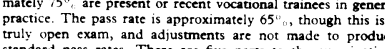

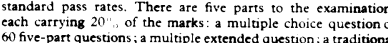

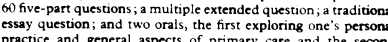
dissussing clinical cases
Since it is inception in the early 1950 s the Royal College

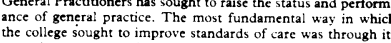

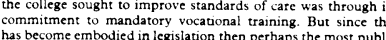

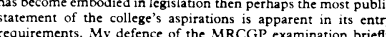

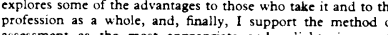

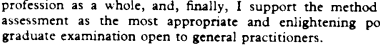

Benefits to the individual

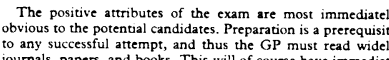

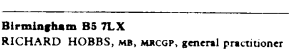

benefiss in improving levels of knowledgec in many areas of
Benceral practice. Thesc include not only the clininal

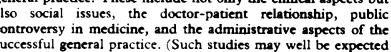

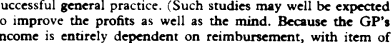

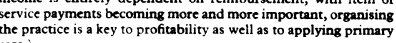

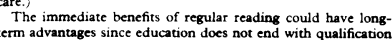

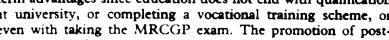

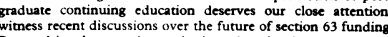

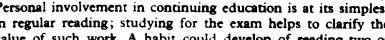

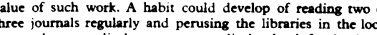

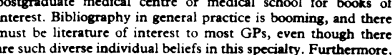

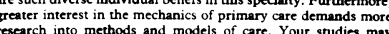
provide the stimulus to a artemptet rials and mand also provide the

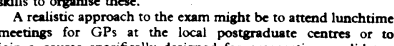

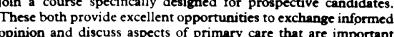

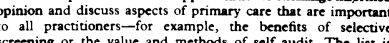

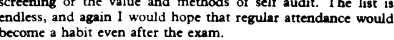

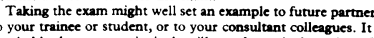

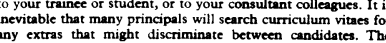

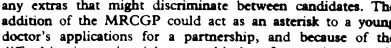

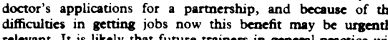

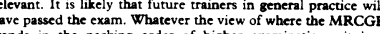

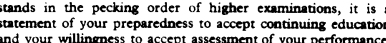

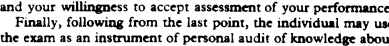

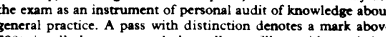

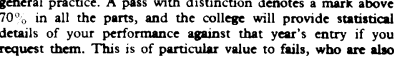

oed

offered specific courses should they wish to examine defficiencies
and retake the cexam Having become a member of the Royal
Cod

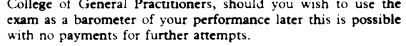

Benefits to che profesestion

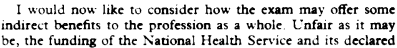

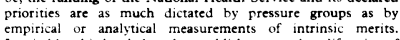

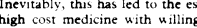

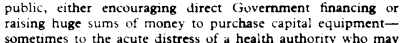

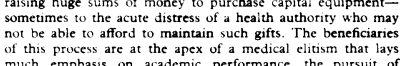

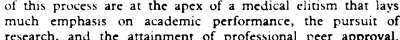

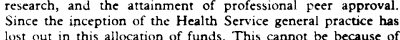

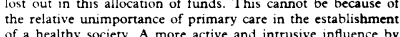

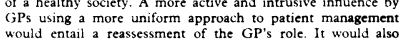

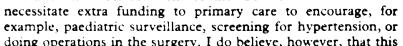

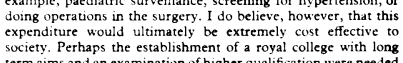

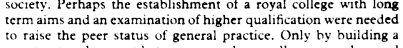

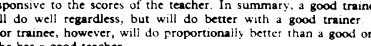

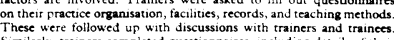

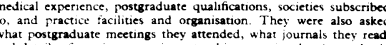

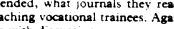

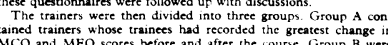

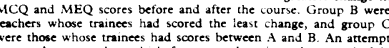

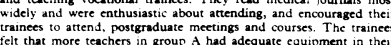

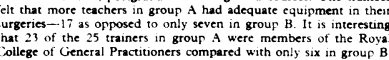

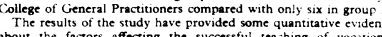

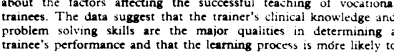

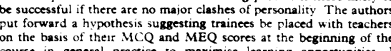

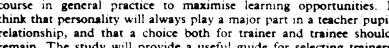

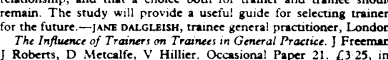

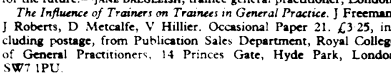

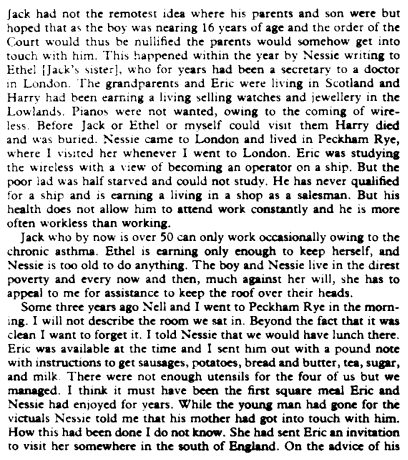

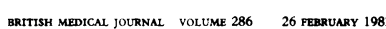

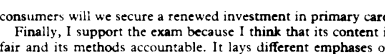

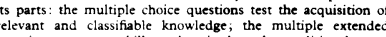

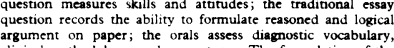

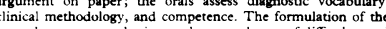

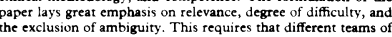
craminers pore over the sesarate parts to produce suitable
quussions, and then all of them actually sit the whole paper to Ichieve standardisation.
It has been said that to produce a higher qualification withour

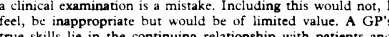

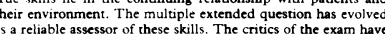

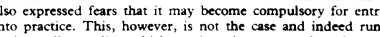

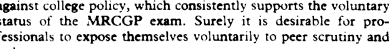

Biblography

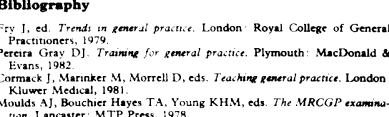

Diary of Urban Marks: 1880-1949

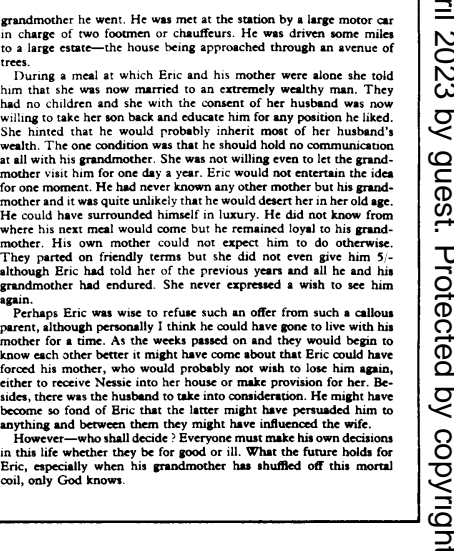

